\title{
Belief, Faith, and Hope: On the Rationality of Long-Term Commitment
}

\author{
ElizABeth JACKSON \\ Australian National University / Ryerson University
}

I examine three attitudes: belief, faith, and hope. I argue that all three attitudes play the same role in rationalizing action. First, I explain two models of rational action-the decision-theory model and the belief-desire model. Both models entail there are two components of rational action: an epistemic component and a conative component. Then, using this framework, I show how belief, faith, and hope that $\mathrm{p}$ can all make it rational to accept, or act as if, $\mathrm{p}$. I conclude by showing how my picture can explain how action-oriented commitments can be rational over time, both in the face of counterevidence and in the face of waning affections.

\section{Introduction}

The ability to keep a commitment over a long period of time is a crucial aspect of our lives. Completing grad school, picking up a new instrument, getting in shape, marriage, and religious commitment all require it. But keeping these sorts of commitments isn't without obstacles. Sometimes, we get counterevidence that makes us question whether we ought to have made the commitment in the first place. Is this workout program really the best means of getting healthy? Does God really exist? Other times, we lose the desires that underlie our original commitment. Is getting fit really worth running outside in the cold every day? Is God someone I should want to commit my life to, regardless of whether theism is true?

In this paper, I argue that the relationship between three attitudes, namely, belief, faith, and hope, shows how we can overcome epistemic and conative obstacles that we encounter in our commitments. Specifically, my thesis is that paradigm cases of belief, faith, and hope all play the same role in rationalizing long-term, action-oriented commitments. The relation between these three attitudes can explain how a commitment to act can be rational, in the face of both counterevidence and waning affections. ${ }^{1}$

\footnotetext{
${ }^{1}$ See Morton and Paul (2019) for a complimentary paper on the rationality of long-term commitment, in which they discuss 'grit', the capacity for perseverance that enables one to
} 
This paper is structured as follows. In $\S_{2}$, I discuss acceptance (that is, acting as if some proposition is true). To illuminate what makes acceptance rational, I describe two models of rational action. I show how, on both models, there are two components of rational action: an epistemic component and a conative component. Then, in $\S_{3}$, I argue that paradigm cases of belief, faith, and hope that $\mathrm{p}$ all rationalize accepting that $\mathrm{p}$. I conclude in $\$ 4$ with two upshots. The first is about the diachronic rationality of commitment, and the second about the special role that faith plays in justifying long-term commitments.

A few caveats before I begin. First, my focus is on propositional versions of belief, faith, and hope, rather than, for example, belief in a concept or faith in a person. Second, this paper will provide a general, descriptive characterization of how these propositional attitudes function, with an eye toward showing how these states can rationalize action. In the same way that decision theory takes credences and utilities as inputs to determine rational action, but is not meant as a tool for evaluating the rationality of, for example, a credal state, I will show how certain propositional attitudes, that is, belief, faith, and hope, make actions rational for that agent. The purpose of this paper is not to give a story about rational belief, faith, or hope, but instead to give a general description of these states and explore their relationship to rational action. Finally, the main goal of this paper is not to provide a novel theory of the nature of belief, or faith, or hope. Instead, this paper explains existing theories of each attitude, borrowing from current accounts to draw connections between them. Its contribution involves the way that belief, faith, and hope come together to rationalize our long-term commitments via acceptance. This, in turn, tells us something interesting both about the relationship between the attitudes and about diachronic rationality.

\section{Acceptance and what justifies it}

\subsection{Acceptance}

Accepting that $\mathrm{p}$ is acting as if $\mathrm{p}$. When one accepts a proposition, one treats it as true in one's practical reasoning, and, upon taking action,

achieve long-term goals. However, Morton and Paul endorse an evidential threshold account of rational long-term commitment that I reject, for reasons discussed in \$3.3. See Rioux (2020a) for a response to Morton and Paul. For more on the diachronic rationality of commitment, see Buchak (2017b) and Rioux (2020b). For more on the practical rationality (and moral permissibility) of faith and hope, see Jeffrey (2017). 
acts as if it were true (Cohen 1989; Cohen 1992; Weirich 2004; Audi 2008; Locke 2015). According to Jonathan Cohen (1992, p. 4), when one accepts a proposition, one includes that proposition... among one's premises for deciding what to do or think in a particular context'. And William Alston $(1996$, p. 8$)$ notes that 'to accept that $p$ is to "take it on board," to include it in one's repertoire of (supposed) facts on which one will rely in one's theoretical and practical reasoning and one's behaviour'.

Acceptance is not, in my view, a fundamental mental state. In fact, it is an action rather than a state-Cohen calls it a 'policy'. Acceptance is rationalized by combinations of mental states (more on this soon). Acceptance is also propositional-because we accept propositions, acceptance has propositional content. The focus of this paper is action-oriented commitments, and since I am concerned with propositional versions of belief, faith, and hope, acceptance is a good candidate for their action-oriented propositional analogue. Thus I will focus on acceptance.

\subsection{What justifies acceptance}

What justifies accepting a proposition? Since acceptance is a commitment to act (that is, act as if a proposition is true), what justifies acceptance is what justifies action. According to two major theories of rational action, rational action is a function of two inputs: an epistemic component and an axiological/conative component. The first theory of rational action is decision theory. According to decision theory, how you ought to act is a function of two things: the probability of various propositions, and a utility function that reflects the value of various states of affairs (see Briggs 2014). On an orthodox decision theory model, you ought to choose the action that maximizes expected value, given your credences (subjective probabilities) and your utility function. The second theory of rational action is the beliefdesire model. On this model, you ought to act in ways that are appropriate, given your beliefs and your desires (see Davidson 1963; Bratman 1987). As with decision theory, on a belief-desire theory of rational action, how you ought to act is a function of something epistemic (beliefs) and something axiological (desires). A little more on each of these components.

The epistemic component of rational action is a representation of the world, for example, the agent's beliefs and/or credences. This component is truth-tracking, responsive to evidence, and evaluable from a primarily epistemic point of view. It has a mind-to-world direction of fit. Critical to note for our purposes is that acting as if $\mathrm{p}$ can be rational even if one has no desire that $\mathrm{p}$ be true, if one has enough 
confidence or evidence that $\mathrm{p}$ is true. We routinely rationally act on things we don't want to be true all the time. For example: I failed the exam, so I had better act as if I failed and study for my re-take, even though I strongly desire that I didn't fail. I missed my flight, so I had better try to book another one, even though I wish that I hadn't missed it. There are many cases where a belief that $\mathrm{p}$ or a high credence that $\mathrm{p}$ justifies acting as if $\mathrm{p}$, apart from any desire for $\mathrm{p}$ to be the case.

The conative/axiological component of rational action is about what is valuable or desirable, for example, the agent's desires or utility function. It has a world-to-mind direction of fit. This component, unlike the epistemic component, does not (necessarily) involve evidence or justification for $\mathrm{p}$. One can desire $\mathrm{p}$, even rationally, while believing not-p or having a very low credence in $\mathrm{p}$. What matters for this component is not whether $\mathrm{p}$, but how good or bad it would be if $\mathrm{p}$. Further, accepting $\mathrm{p}$ can be rational even if one's credence is quite low, if one's desires or utilities are strong/high enough (for example, if something very valuable would be gained if $\mathrm{p}$ were true). Consider several examples.

First, suppose your brother goes missing. He has been missing for a long time, and there is a lot of evidence he is dead. Because of this evidence, you believe and/or have a very high credence that he is dead. Nonetheless, you think there is some chance he might be alive. Because it would be so good if he were alive and you found him, you act as if he is alive, by putting up missing posters, spending lots of time searching for him, and so on. The goodness of finding him motivates you to do this, despite your low credence that he is living.

Second, suppose you are hiking in an uninhabited area and you get lost. You run out of food and water and wander around for a very long time. Finally, you find a path back to civilization, but as you follow it, it leads you to a steep and wide crevice-just wide enough that there's a chance you can jump across, but, given your jumping abilities, it is unlikely that you will make it. However, making this jump is your only chance of survival. You ought to act as if you will make the jump and at least try to do so, even though you have little evidence that you will make it-because of how good it would be if you succeeded (even apart from self-justifying considerations). ${ }^{2}$

\footnotetext{
${ }^{2}$ This case is adapted from James (1897). Some have noted that, if you believe you can make this jump, it will make it more likely you will make the jump, because you will gain selfconfidence, energy, and zeal which will help you jump further. In this, the belief you will succeed creates evidence for itself (see Jackson 2020). However, here, I am interested in what
} 
Finally, suppose you are a parent. It is winter and it has recently snowed quite a bit, and you take your children outside to play in the snow. You live next to a lake and your children ask if they can go play on the frozen lake. It has been below freezing for a significant amount of time and you know that lakes in your area are often thickly covered in ice and safe to walk on. Thus you have a low credence that the ice will break. However, your children are young and if the ice broke, their lives would be in danger. Thus it is rational to insist your children stay far away from the frozen lake, acting as if it will break, even though your credence it will break is very low-because it would be very bad if the ice broke while your children were playing on it.

These cases show that rationally accepting $\mathrm{p}$ comes apart from belief or a high credence that $\mathrm{p}$, depending on what is at stake in a particular decision context. In this, accepting $\mathrm{p}$ can be rational, even if it is unlikely that the world is such that $\mathrm{p}$ or there is good evidence favouring not-p. In what follows, I will assume that rational action (and thus rational acceptance) is a function of merely the epistemic and the axiological, as these two models suggest. ${ }^{3}$ I will argue that, given this, paradigm cases of rational belief, faith, and hope that $p$ all entail accepting that $p$.

\section{Three attitudes that make acceptance rational}

\subsection{Belief}

Belief is the attitude of taking something to be the case or regarding it as true (Schwitzgebel 2019). Belief generally requires quite a

makes the action rational, rather than what makes the belief rational, so I set aside these selfjustifying cases.

${ }^{3}$ Recently, Lara Buchak has argued that rational action is a function of three components, rather than two: the epistemic, the axiological, and a risk function that represents an agent's attitudes about worst-case scenarios. She argues that risk-weighted expected utility (REU) theory has benefits over traditional expected utility (EU) theory, such as providing a solution to the Allais Paradox (see Buchak 2013; Buchak 2017a). My assumption here is consistent with REU theory insofar as the agent's risk function is convex or linear; in the former, the agent is risk-inclined, REU theory will permit all actions permitted by EU theory (and more). In cases where the agent's risk function is linear, REU theory and EU theory are equivalent. However, Buchak's model conflicts with my assumption in cases where the agent's risk function is concave and the agent is risk-averse; in these cases, REU theory doesn't permit all actions permitted by EU theory. For the sake of simplicity, I will utilize a model of rational action that is a function of two elements, rather than three, but it is worth noting that my conclusions are also consistent with the verdicts of Buchak's REU theory, except in the case where the agent's risk function is convex. Thanks to an anonymous referee for helpful clarification on this point. 
bit epistemically (for example, fairly strong evidence). We ought not, and often will not, believe $\mathrm{p}$ if our evidence strongly favours not-p. In this, belief is a state that is primarily sensitive to epistemic factors, like evidence and truth. On the other hand, belief that $\mathrm{p}$ has no implications for desire that $\mathrm{p}$. As noted above, there are many things we believe (that we failed the test or that we missed the flight) that we have no desire at all to be true. Thus belief has a strong epistemic component but no essential conative component.

Nonetheless, the robust epistemic component of belief makes accepting $\mathrm{p}$ rational in paradigm cases of belief that $\mathrm{p}$. Usually, when we believe that $\mathrm{p}$ is true, we act as if $\mathrm{p}$. I believe coffee will wake me up, so I drink it when I am tired in the morning. I believe my car is parked north of campus, so I walk that way when I leave the office. As Cohen (1989, p. 368) notes, 'we often accept what we believe and believe what we accept'.

Furthermore, recently some have suggested that part of the functional role of belief is a disposition to treat $\mathrm{p}$ as true in one's reasoning (for example, Wedgwood 2012; Ross and Schroeder 2014). This suggestion is plausible and makes sense of the idea that belief and acceptance often go together. Yet the connection between believing $\mathrm{p}$ and treating $\mathrm{p}$ as true in one's reasoning is not seamless. Depending on the gains and losses associated with not-p, it might be still rational to act as if not-p (as long as one doesn't have credence 1 in p). In the frozen lake example above, you might believe the ice is solid but not accept the ice is solid because of the risk of your children falling in. Or you might believe your friend's spouse is cheating on her but not accept it, and, for example, refrain from telling your friend about your belief, because if you are wrong, doing so would do a lot of unnecessary damage to their marriage. Thus believing $\mathrm{p}$ entails a disposition to treat $\mathrm{p}$ as true in one's reasoning, but this disposition is defeasible (see Ross and Schroeder 2014; Jackson 2019). Thus, although there are exceptions, paradigm cases of belief that $\mathrm{p}$ entail acceptance that $\mathrm{p}$.

\subsection{Faith}

Faith is an attitude that has received ample philosophical attention as of late (for overviews, see Bishop 2016; Rettler 2018). One of the primary controversies in the faith literature involves the relationship between faith and belief: specifically, whether faith that $p$ entails 
belief that $\mathrm{p} .{ }^{4}$ Ultimately, either view on this controversy is consistent with my arguments in this paper. However, I will assume, for two reasons, that faith that $\mathrm{p}$ does not entail belief that $\mathrm{p}$ for two reasons. First, if faith does entail belief, this makes my arguments easier and, this, in some sense, stacks the deck in my favour. This is because we have already established that there is a tight connection between belief and acceptance, and if faith is just a kind of belief, then there is no need for a separate argument connecting faith and acceptance. Second, as will become clearer later in the paper, the model I propose on which belief, faith, and hope can make commitments rational over time is more interesting on the supposition that faith is possible without belief.

Assuming faith doesn't entail belief, what can we say about the nature of faith and its relationship to acceptance? First, faith generally has a weaker epistemic component than belief; as Alston (1996, p. 12) notes, '[F]aith that has at least a strong suggestion of a weak epistemic position vis-a-vis the proposition in question'. That is, faith requires less evidence and/or is consistent with a lower credence than belief. One reason to think this is that it may sound odd to say one has faith that $\mathrm{p}$ when one is maximally certain that $\mathrm{p}$, whereas belief is undoubtedly consistent with maximal certainty. Faith's epistemic component is nonetheless a moderate one; it is natural to think that faith that $\mathrm{p}$ is inconsistent with belief that not-p or an extremely low credence in p (see Howard-Snyder 2013). For example, it is hard to make sense of the idea that one could have faith that God exists and believe that God does not exist.

Faith further differs from belief in that it has an essential conative component: faith that $\mathrm{p}$ requires a desire for $\mathrm{p}$ to be true. ${ }^{5}$ To illustrate, suppose my friend Greta is running a marathon. I tell her I have faith that she will win the marathon. At the same time, I strongly desire that she loses the marathon. This seems impossible; I cannot have faith that $\mathrm{p}$ if I don't desire $\mathrm{p}$ to be the case. Thus, while faith has a weaker epistemic component that belief, it has a stronger conative component than belief.

\footnotetext{
${ }^{4}$ Mugg (2016) and Malcolm and Scott (2016) argue that faith entails belief. Pojman (1986), Audi (1991), Alston (1996), Kvanvig (2013, 2016), Howard-Snyder (2013) and McKaughan (2013) argue that faith does not entail belief.

5 This point is defended by Alston (1996, p. 12), Howard-Snyder (2013), Kvanvig (2013), and McKaughan (2013), among others.
} 
Faith's moderate epistemic component and moderate conative component mean that when one has faith, one fulfils the two conditions of rational action explained above. For this reason, those with faith that p ought to, and often will, accept $p$ (see Alston 1996). ${ }^{6}$ If one has faith that $\mathrm{p}$, one should treat $\mathrm{p}$ as true in one's decision making and act on $\mathrm{p}$. In this, having faith in a proposition requires having a policy of adopting that proposition, 'taking it on board' in one's reasoning and acting.

In order to dispel potential counterexamples to the suggestion that one ought to accept propositions of faith, it is critical to note that what it means to accept a proposition is not always straightforward. For example, suppose someone has faith that God exists. Nonetheless, they teach at a secular school and they refrain from proselytizing their students and co-workers. It may seem as thoughmy view would entail that this means they don't accept that God exists, and thus are irrational or do not actually have faith. ${ }^{7}$ However, this is too quick. They can treat the proposition that God exists as a premise in their practical reasoning without, for example, proselytizing everyone around them-what premising God's existence ultimately looks like depends on their other beliefs/credences and desires. They might have faith God exists, but also believe that God does not want them to defy authority figures. Or they might think God doesn't want them to force their faith on the uninterested. Thus whether one accepts $\mathrm{p}$ is a complicated matter, and what exactly this looks like requires a holistic picture of one's mental states. Nonetheless, I maintain that those with faith that a proposition is true ought to accept that proposition.

A second potential counterexample to this involves a case where you have faith that $\mathrm{p}$ but you are faced with a ridiculous bet on which,

\footnotetext{
${ }^{6}$ While Alston also closely links faith and acceptance, he goes one step further and argues that acceptance is a primary cognitive component of faith, especially religious faith. In this, Alston seems to treat acceptance as its own fundamental cognitive attitude (1996, p. 10). This picture of acceptance and faith is misguided. Since acceptance is, as Alston acknowledges, essentially just acting as if $\mathrm{p}$, it is odd to treat it as a cognitive attitude or suggest it is a cognitive component of faith. Acceptance is a commitment to act on a proposition, which is merely the result of certain combinations of one's epistemic and conative states. In this, acceptance is, at best, a 'mental state' only in the sense that it results from certain beliefdesire combinations. Acceptance is surely not its own sui generis mental state. Thus I agree with Alston that faith is closely tied to acceptance, but I disagree that acceptance is a cognitive attitude that is a key part of faith. Rather, that faith entails or leads to acceptance is a more plausible way of capturing the spirit of Alston's view. (For another criticism of Alston, see Vahid 2009.)
}

7 Thanks to Jack Warman. 
for example, you get $\$ 1$ if $p$ and are tortured forever if not-p. Are those with faith really required to take this sort of bet? One response to this style of case is to say that refusing to take the bet is evidence that you have given up your faith that $\mathrm{p}$ (and note that giving up your faith that $\mathrm{p}$ might be the rational response in this circumstance). At the same time, there seems to be something praiseworthy about certain cases of people who do not give up their faith, even in the face of remarkable odds - this may be why in religious traditions, martyrs are admired and considered to be role models of unshakable faith. A second response is to weaken the link between faith and acceptance, and maintain that those with faith that $\mathrm{p}$ will accept $\mathrm{p}$ in most circumstances, but there can be extreme circumstances where agents have faith but nonetheless need not accept the propositions of faith. Since the main thesis of this paper is that belief, faith, and hope enable us to maintain commitments over time, it is not crucial that all cases of faith involve rational acceptance. Even if there are cases where faith and acceptance come apart, I maintain that faith almost always involves rational acceptance, and does so more than belief and hope.

\subsection{Hope}

I begin by clarifying the notion of hope I have in mind. First, as noted above, I'm interested in hope that has propositional content, as opposed to general, content-less hope (see Marcel 1951, p. 26 and Godfrey 1987 for more on this distinction). Second, I'm interested in a strand of hope that is closely tied to the rationality of action (see, for example, Martin 2013's incorporation account of hope; Born 2018). ${ }^{8}$ Some authors refer to this more action-oriented strand of hope as hopefulness (Martin 2013, p. 69; Bloser and Stahl 2017, p. 367), but for the sake of simplicity, I will generally just use the term 'hope'.

This second point is significant because of so-called 'prosaic' or mundane cases of hope-for instance, my hope that the cashier at the grocery store has a nice day, that my distant cousin gets the job he wants, or that my picnic doesn't get rained out. ${ }^{9}$ While I acknowledge these are cases of genuine hope, they are generally not hopes that are essential to our long-term commitments or ones that we build our lives around. The practical import of prosaic hopes is minimal,

${ }^{8}$ Thanks to an anonymous referee.

9 Thanks to an anonymous referee. For further discussion of prosaic hopes, see Martin (2013, pp. 7off) and Bloser and Stahl (2017, pp. 368-9). 
especially when compared to that of profound hopes; contrast my hope that the cashier has a nice day with the religious person's hope for the afterlife or the political activist's hope for world peace (see Chae forthcoming). The latter cases involve stronger desires and have more significant practical impact. Here, I concern myself primarily with these more profound, life-shaping hopes.

Hope's epistemic component is significantly weaker than both faith and belief. Hope that $\mathrm{p}$ is consistent with a very low credence in $\mathrm{p}-$ arguably, with most credences in $\mathrm{p}$ except $0 .{ }^{10}$ In this, all hope that $\mathrm{p}$ requires, epistemically, is an acknowledgment that there is some chance that $\mathrm{p}$. Thus those with hope that $\mathrm{p}$ have not ruled out the possibility of $\mathrm{p}$, but they may nonetheless think $\mathrm{p}$ is very unlikely (see Martin 2013, p. 11; Meirav 2009, pp. 217-9).

On the other hand, desire is a distinctive feature of hope. As Born (2018, p. 107) notes, 'Hope is essentially a desire, a pro-attitude...' Almost everyone in the hope literature maintains that a desire for the proposition in question is a necessary condition for hope. ${ }^{11}$ The following sentences further support the claim that desire is constitutive of hope:

\#I hope that you have a nice day, but I don't desire that you have a nice day;

\#I hope that God exists, but I don't want God to exist;

\#I want my team to win the championship, but I hope they don't win the championship;

\#I desire for it to snow tomorrow, but I hope it doesn't snow tomorrow.

All these sentences sound odd, and a good explanation for this is that desire is central to hope. In both mundane and non-mundane cases, one of the predominant components of hope is desire. In prosaic cases of hope, such desire exists, but may be mild. However, when it comes

\footnotetext{
${ }^{10}$ Hope may be inconsistent with credence 1 or other very high credences. In most (nonsceptical) contexts, it seems odd to say ' $I$ hope that $1+1=2$ ', or 'I hope that I exist', or generally, 'I know that $\mathrm{p}$ and I hope that p'. (For more on the relationship between hope and knowledge, see Benton 2019; Benton forthcoming.) As Martin (2013, p. 69) notes, hope that $\mathrm{p}$ may be consistent with any credence in $\mathrm{p}$ between, but excluding, 1 and $\mathrm{o}$.

${ }^{11}$ See Downie (1963, p. 248); Day (1969, p. 89); and Born (2018). A belief that p is possible and a desire for $\mathrm{p}$ are widely taken to be necessary conditions for hope. However, they may not be jointly sufficient for hope. Among other things, if they are sufficient, it is unclear what distinguishes hope from despair (see Meirav 2009); but see Milona (2019) for a defence of the belief plus desire view of hope.
} 
to profound hopes involving propositions linked to our personal, long-term life commitments (my primary focus), the desires underlying our hopes are often very strong.

It is plausible that, especially in profound cases, hope's conative component is even stronger than that of faith. In other words, generally, we have a stronger desire for $\mathrm{p}$ when we hope that $\mathrm{p}$ than when we have faith that $\mathrm{p}$. There are at least two reasons to think this. First, if hope merely involves desiring something to the same degree as faith but with less evidence or a lower credence, hope seems like faith's 'younger sibling. ${ }^{12}$ Hope would merely be a fallback for those who used to have faith but lost confidence or evidence. On this view, hope seems to lose its power and distinctiveness. And we have good reason to think that hope is more than a mere fallback and that it has its own unique motivating force. Hope is considered a virtue in many traditions - both secular and religious - and not merely for those who lose faith, but a virtue in its own right (Mittleman 2009, ch. 2; Amiri and Keys 2012, Milona forthcoming). Hope is one of the three Christian theological virtues, alongside faith and love. Note that hope is listed next to faith, with no indication that it is subsumed by faith or a backup for those who have lost faith (see 1 Cor. 13:13; Augustine c. 420, II.7; Aquinas 1265-1274/1912, 2.2.17). Other traditions, including Judaism, treat hope in a similar way (see Albo 1930). Maintaining that hope's conative component is stronger than faith's is one way to avoid this bleak picture of hope, and capture the widely-supported idea that hope is a virtue and has value that goes beyond the value of faith. ${ }^{13}$

${ }^{12}$ Thanks to Sam Newlands.

${ }^{13}$ Although, note that some authors-for example, Bovens (1999), Walker (2006), Martin (2013), Calhoun (2018), and Stockdale (2019) - have challenged the idea that hope is a virtue and crucial for all humans to cultivate. For one, hope can be risky, and can lead to wishful thinking and practical irrationality. Two, some cannot cultivate hope due to cognitive impairments. On the first point, note that hope's being a virtue is consistent with the claim that it is sometimes irrational. Consider a similar case: courage is a virtue, but one could be irrationally courageous by putting oneself in unnecessarily risky situations for little payoff. A virtue theorist might explain these cases by emphasizing the importance of cultivating the virtues together-if one has too much hope or courage but no wisdom or prudence, then they might take unnecessary risks. Thus, insofar as the fully virtuous person is hopeful, her other virtues, like wisdom, might prevent her from engaging in wishful thinking. Second, it is true that some cannot cultivate hope due to cognitive impairments; the same is true for other virtues as well. A virtue theorist might modify their account to say that one should cultivate virtues insofar as one is able. Thanks to an anonymous referee for this objection. 
Further, note that this doesn't mean that hope cannot be, in some cases, an alternative for those who used to have faith-it makes sense to say: 'I desire that God exists, and though I have lost faith that God exists, I still have some hope'. ${ }^{14}$ In fact, one of the main claims in this paper is that moving from faith to hope is part of what enables us to maintain our long-term commitments in the face of a loss of evidence. However, the agents who move from faith to hope must initially have a strong enough desire for $\mathrm{p}$ to count as hoping; without this, agents who lose faith ought to give up their commitment. Thus, while hope should be considered a fallback for faith in this sense, it is not merely needed for a small subset of people who fail to have faith: hope has its own power, distinct from faith.

The second, related reason to think that hope's conative component is even stronger than that of faith is related to a puzzle discussed by some in the hope literature. This puzzle involves explaining how hope can have distinct motivating force in arduous circumstances, especially when the probability of the hoped-for proposition is quite low (see Pettit 2004, p. 154; McGeer 2004, p. 104; Martin 2013; and Calhoun 2018). If hope requires an especially strong desire for the proposition in question, this can at least partially explain the motivating power of hope, especially in exceptionally difficult situations. And if the desires of the hopeful are often stronger than those associated with faith, this can explain why, in some cases, hope seems to motivate as well as faith, despite faith's having a stronger epistemic component. Of course, hope's robust conative component might not be the full story about how hope motivates through difficulties; our theory of hope may need to be supplemented with another feature of hope, such as Calhoun's theory about the way hope provides a 'phenomenological idea of the future' (2018) or Chignell's focus theory of hope (2021). ${ }^{15}$ Here, I merely intend to provide necessary conditions for hope. Nonetheless, associating hope with especially strong desires can at least somewhat explain the way hope uniquely inspires.

Often, those with hope that $\mathrm{p}$ ought to accept $\mathrm{p}$. While hope is consistent with a wide range of credences, even quite low ones, hope's conative component has force where hope's epistemic component falls short, and this often justifies the hopeful in acceptance. This is

\footnotetext{
14 Thanks to an anonymous referee.

${ }^{15}$ Thanks to an anonymous referee. But see Milona (2019) for an argument that these extra features of hope are unnecessary.
} 
because there will be a very good outcome if the hopeful person acts as if $\mathrm{p}$ and $\mathrm{p}$ turns out to be true, and this good outcome can outweigh the potential losses associated with acting as if $p$ (for example, if not-p turns out to be true) and the gains of taking other courses of action. Consider several examples. I may have a student who has failed to turn in all his previous assignments on time. Thus my credence he will turn in the next paper on time is quite low. Nevertheless, I also have a strong desire for him to succeed in the course and turn in his work when it is due. Thus I still assign him to a peer review group, even though participation in the group requires one's paper to be finished promptly. My evidence of his past behaviour may result in my having such a low credence that I cannot even have faith he will turn the paper in on time, but I nonetheless hope he will, and my hope justifies my acting as if he will-because of how good it would be if I assigned him to a group and he did turn this paper in on time. Born (2018, p. 113) provides another case: suppose you don't know your neighbour very well and don't have evidence that she is a nice person; you may even have some positive evidence that she is not a nice person. Nonetheless, you hope that she's a nice person, and in virtue of this, act as if she's a nice person, and, for example, invite her over for a barbeque or let her borrow eggs. These actions are potentially rational, especially if your counterevidence is not decisive.

There are more serious examples as well. For instance, Martin (2013, pp. 108-11), Duckworth (2016), and Morton and Paul (2019, pp. 1989) discuss 'trials': cases of desperate hardship, in which one experiences captivity or alienation and doesn't have good alternatives available. Trials include facing severe obstacles to one's central life projects, such as enduring a serious disease, surviving in a concentration camp, and coping with the fact that one's brother has gone missing in the case discussed above. In these cases, one might have very good evidence that one will never overcome the trial, but nonetheless rationally continue to act as if one will-because of how good it would be if one persevered and overcame the hardship, and the fact that one doesn't have good alternative courses of action available. Acting as if one will find one's missing brother or as if one will survive a lifethreatening illness seem like rational responses to finding oneself in a desperate circumstance, and it is natural to see the agents in question as acting on the basis of hope that they can overcome the hardship. In most cases involving some trial, hope rationalizes acceptance.

Nonetheless, unlike faith, hope does not always rationalize acceptance. As Alston (1996, p. 24) notes, '... acceptance is quite different 
from hope. I can hope that God will grant me what it takes to carry out tasks He gives me without accepting the proposition that He will'. Or consider a second version of the frozen lake case above, in which I am considering whether to walk across a frozen lake. Suppose I hope that the lake is solid-because walking across the lake makes my walk much shorter, and if it is solid, I won't fall in. This mere hope does not rationalize my walking across the lake; walking across the lake seems irrational, especially if the probability that it is solid is low and I'm only doing so to shorten my walk. Here, I hope that p, but it is irrational to act as if $\mathrm{p}^{16}$

One might worry, then, that even if there are cases where hope rationalizes acceptance, there are similar cases where hope doesn't rationalize acceptance, and my view that paradigm cases of hope rationalize acceptance begins to look ad hoc. ${ }^{17}$ Or, put differently: does anything demarcate the cases where hope rationalizes acceptance from those where hope doesn't rationalize acceptance?

In response, a significant part of the difference involves the possibility of not-p. More specifically, in cases where an agent has quite a bit to lose if not-p and the probability of not-p is high, acting as if $p$ may be irrational, even if the agent hopes that $\mathrm{p}$. This is why, in the second version of the frozen ice case, it is not rational to act as if the ice is solid, even if one genuinely hopes that it is. If the ice is not solid and one falls in, this consequence is especially bad-much worse than the value gained in shortening one's walk. But consider a third frozen ice case: one's child is trapped, and walking across the ice is the only way to save the child. Suppose again that it's possible but unlikely the ice is solid. There is even more to be gained or lost, depending on whether the ice holds, but in this third case, one's desire that the ice holds is even stronger. Then one's hope that the ice is solid might justify accepting that the ice will hold, in order to try to save one's child. In this third case, acceptance is rational, partially due to the fact that the gains associated with $\mathrm{p}$ are higher than the losses associated with not-p.

Along similar lines, in the cases of trials discussed above, part of the reason hoping for $\mathrm{p}$ justifies acting as if $\mathrm{p}$ is that there is not much to be lost if not-p-the situation is already dire. Generally, the more there is to be gained if $p$, and the less there is to be lost if not-p,

\footnotetext{
16 Thanks to an anonymous referee for this case.

17 Thanks to an anonymous referee.
} 
and the higher the probability of $\mathrm{p}$, the more likely it is that one can rationally act on one's hope that $\mathrm{p}$. And in the cases of profound hope we've focused on, these conditions will often be met: one has a very strong desire that $\mathrm{p}$ be the case and one has centred one's life projects around $\mathrm{p}$. Consider again the political activist who hopes that we can someday achieve world peace or the religious person who hopes that there is an afterlife. In these cases, there is much to be gained upon accepting $\mathrm{p}$ if $\mathrm{p}$, and this outweighs the losses associated with accepting $\mathrm{p}$ if not-p.

This point is further reinforced by the fact that, arguably, cases where one hopes for something merely for some small benefit, for example, hoping that the ice is solid to shorten one's walk, are mundane cases of hope. Mundane hopes will often not rationalize acceptance, which is part of the reason I set them aside at the beginning of this section. Thus, especially when we narrow our focus to profound hopes, hope often rationalizes acceptance.

\section{Upshots}

\subsection{The diachronic rationality of commitment}

The central upshot of my view is that it can explain the diachronic rationality of commitments to act, both in the face of waning affections and in the face of counterevidence. Let us consider each in turn.

First, agents can be justified in acting as if $\mathrm{p}$ even if they increasingly lose the desire for $\mathrm{p}$ to be true, as long as they retain sufficient evidence for p. Many commitments are initially motivated by a strong desire or affect that motivates the initial commitment: for example, the determination of those beginning a new workout routine for the first time, the enthusiasm many have when they begin graduate school, and the overwhelming affection of the newly married. One may start by believing, having faith, and hoping that the propositions relevant to one's commitment obtain. ${ }^{18}$ However, the affections

\footnotetext{
${ }^{18}$ Here, an anonymous referee raises an interesting question: can you believe that $\mathrm{p}$ and hope that $\mathrm{p}$ at the same time? Prima facie, one might think not, given arguments that hope is incompatible with knowledge (Benton 2019; Benton forthcoming) and with certainty (Martin 2013, p. 69; see also footnote 10 of this paper). However, belief is weaker than both knowledge and certainty. Since believing $\mathrm{p}$ is widely taken to be consistent with credences in $\mathrm{p}$ below 1 (because, for example, we are more confident in some of our beliefs than others, and many everyday beliefs are not ones in which we are maximally certain), it is natural to think that believing $\mathrm{p}$ is consistent with acknowledging that there is a chance that not-p (see Jackson 2019). This opens up the possibility that one could believe $p$, have a strong desire for $p$, and
} 
associated with the latter two states may fade over time, and the desires that motivated the initial commitment may grow weaker and weaker. Nonetheless, one's beliefs can enable one to follow through and stick to the workouts, graduate school, or marriage, even absent the initial desires and affections. In the religious case, agents may lose the desire for God to exist, but nonetheless carry out their theistic commitment because they continue to believe that God exists. They may no longer say that they hope that God exists, and they may not even have faith that God exists, but their belief that God exists enables them to endure and makes their acceptance of God's existence rational. In the face of discouragement, it is sometimes advised that one ought to rely on what one knows or believes to be true, rather than one's fluctuating desires or feelings. This may capture something analogous to what I have in mind when I suggest that the epistemic component of commitment can enable agents to rationally carry out long-term projects in the face of waning affections.

This first point is essentially established by the cases in which belief rationalizes acceptance apart from desire, such as the failed exam case in \$2.2. In this, it is primarily a point about the nature of belief. ${ }^{19}$ However, if my argument that hope has a stronger conative component than faith is successful, this opens up a second possibility: there are cases where one hopes that $\mathrm{p}$, then loses some desire that $\mathrm{p}$, but still has enough evidence for $p$ and desire for $p$ that one has faith that $\mathrm{p}$, and thus continues to rationally act as if $\mathrm{p}$. In the face of the loss of desire, one can move from hope to faith without being forced to give up a commitment. Thus this point need not be only about belief, although the cases of belief rationalizing acceptance may be the most typical.

Second, agents can be justified in accepting $\mathrm{p}$ even if they get significant counterevidence that drastically lowers the probability of $p$, as long as it doesn't lower the probability of $\mathrm{p}$ to $\mathrm{o}$. They do so by relying on their belief that $\mathrm{p}$, then their faith that $\mathrm{p}$, and then their hope that p. For example, suppose someone is a committed religious believer and both believes and accepts that God exists. Then they gain counterevidence, for example, they experience serious evil in the world and see that this counts against the existence of an all-powerful, all-good

acknowledge there's a chance that not-p, and on this basis, hope that p. See Born (2018, p. 109) for further discussion on the relationship between hope and belief.

19 Thanks to an anonymous referee. 
God. Their credence that God exists might decrease and this evidence might even require that they give up their belief that God exists, but they can nonetheless have faith that God exists and continue to accept that God exists. Suppose they gain even more counterevidence, such that their credence is, say, 0.2. Nonetheless, they still maintain that there is a chance that God exists and that God's existing would be a very good thing. Even though they think that God probably does not exist, they also believe that if they were wrong and God did exist, knowing God would be very valuable. Thus they continue to accept that God exists and act as if God exists, by going to church, praying, participating in a religious community, and the like (see, for example, Benatar 2006; Kleinschmidt 2017; and Palmqvist 2019). This can be rational for them, despite the fact their credence is quite low, due to the fact that they think God's existing would be valuable and there would be a huge benefit to doing those things if God turns out to exist.

Further, Benton (2018, pp. 431-3) argues that interpersonal knowledge of God is possible even apart from belief that God exists, given a more general principle that interpersonal knowledge of $S$ floats free from propositions known or believed about $S$ (see also Benton 2017, p. 827). Thus there may be some noteworthy sense in which the hopeful or faithful person described above can count as knowing God, even if they neither know nor believe that God exists. ${ }^{20}$

If, as argued above, both faith and hope can ground rational acceptance, then agnosticism and even atheism are rationally consistent with acceptance that God exists (and interpersonal knowledge of God), as long as one's credence that God exists is not o. As Born (2018, p. 111) notes, '[You can] fail to believe that there is a God, but still hope that there is a God... and in virtue of that still centre (central parts of) your life on the proposition that there is a God'. My model of belief, faith, and hope thus shows how a religious commitment can be rational over time, in the face of evidence that significantly lowers one's credence in theism (or in other religious propositions).

Similar considerations apply to other kinds of commitment as well: one might get counterevidence that indicates that one shouldn't be in graduate school or that one's decision to marry someone wasn't a good one, but because of how good things would be if the evidence

\footnotetext{
${ }^{20}$ Thanks to an anonymous referee.
} 
Table 1: Belief, Faith, Hope, and Acceptance

\begin{tabular}{llll}
\hline & $\begin{array}{c}\text { Epistemic } \\
\text { requirement }\end{array}$ & $\begin{array}{c}\text { Conative } \\
\text { requirement }\end{array}$ & $\begin{array}{c}\text { Involves rationally } \\
\text { accepting p? }\end{array}$ \\
\hline $\begin{array}{l}\text { Belief that } \mathrm{p} \\
\text { Faith that } \mathrm{p}\end{array}$ & High & None & $\begin{array}{l}\text { Most cases } \\
\text { Hope that } \mathrm{p}\end{array}$ \\
Low & Medium & High & Many cases \\
\hline
\end{tabular}

were ultimately misleading and the commitment worked out, one can continue to act on the propositions that initially motivated the commitment. In all these cases, as counterevidence builds, these agents begin with belief, then move to faith, then hope. Yet all these attitudes can rationalize acceptance, and this sustains one's commitments over time, even in light of weighty counterevidence. ${ }^{21}$

Thus my account suggests that the relationship between belief, faith, hope, and acceptance can rationalize long-term commitments in the face of a serious loss of evidence or a serious loss of desire. Table 1 summarizes the model I am proposing:

Before I move on, a quick note about the scope of my claims in this paper. My main thesis is that belief, faith, and hope enable certain commitments to be rational over time. Nevertheless, I do not intend to argue that belief, faith, and hope enable all commitments to be rational over time, or that every instance of these attitudes rationalizes acceptance. As came out in the previous section, there are cases where belief and hope (and maybe faith) are genuinely present, but nonetheless one ought not to accept $\mathrm{p}$. That's perfectly consistent with my goal, namely, to trace a path that agents can take, such that commitment is rational in the face of loss of evidence or desire. And if paradigm instances of each attitude rationalize acceptance, then in a fair number of cases, and indeed in standard cases, the commitment will be rational, even if the commitment isn't rational in all cases.

\footnotetext{
${ }^{21}$ Another model for how long-term commitments can be rational in the face of counterevidence is given by Buchak (2017b). There are two salient differences. First, she focuses on the role of faith in long-term commitments, while my focus additionally includes belief and hope. Second, she discusses cases where there is a diachronic-synchronic conflict, and argues that sometimes agents should privilege the diachronic value of maintaining a long-term commitment over what it is rational for them to do at a time. My account is neutral on this point, and is consistent with the idea that the agents in question can maintain their diachronic commitments without sacrificing synchronic rationality.
} 
Thus focusing on paradigm cases is all that is needed to establish this paper's thesis. In response to the worry that focusing on paradigm cases is ad hoc, I've provided some general principles that demarcate rational from irrational acceptance. I reiterate the principle discussed above: the more there is to be gained if $\mathrm{p}$, and the less there is to be lost if not-p, and the higher the probability of $\mathrm{p}$, the more likely it is that one can rationally act on one's hope that $p$. Many cases where acceptance is not permitted are marked by agents having quite a bit to lose if not-p, such as the agent who believes or hopes the ice is solid, but isn't justified in accepting $p$ because of the risk of falling in. Relatedly, it is critical to note that sometimes it is rational to give up a commitment. This can happen for a variety of reasons. The obvious case is one in which one loses both the desire and the evidence associated with the commitment. But cases where not-p is associated with a serious loss may also mark places where it is rational to relinquish a commitment, depending on one's other beliefs/credences and desires.

\subsection{The unique power of faith}

A second upshot of my account is that, in a key sense, faith, rather than hope or belief, is the most powerful and stable attitude. This is because faith always (or almost always) entails rational acceptance of the proposition(s) of faith, whereas belief and hope more often come apart from rational acceptance. While I maintain that paradigm cases of each state rationalize acceptance, faith is most closely tied to acceptance. In this, faith plays a special role in maintaining one's longterm projects. This captures a natural thought: that faith is a uniquely crucial part of commitment. This isn't to say that belief and hope aren't important: they play a role when one doesn't have the desires needed for faith or doesn't have the evidence needed for faith, respectively. However, my account gives a privileged position to faith, and, insofar as this is pretheoretically plausible, this provides an additional consideration in favour of my view.

\section{Conclusion}

I've argued that belief, faith, and hope all play the same role in rationalizing long-term commitments to act over time. I've shown that on two classic models of practical rationality, rational action is a function of the epistemic and the conative. Given this, belief, faith, and hope can all play the same role in making acceptance rational. Thus our 
long-term projects can overcome two major obstacles: the loss of evidence and the loss of desire. ${ }^{22}$

\section{References}

Albo, Joseph 15th century/1930, Sefer Ha-Ikkarim: Book of Principles, I. Husik (ed. and trans.), (Philadelphia, PA: Jewish Publication Society of America)

Alston, William 1996, 'Belief, Acceptance, and Religious Faith', in J. Jordan and D. Howard-Snyder (eds.), Faith, Freedom, and Rationality (Lanham, MD: Rowman and Littlefield): 3-27

Amiri, Rachel A. and Mary M. Keys 2012, 'Benedict XVI on Liberal Modernity's Need for the 'Theological Virtues' of Faith, Hope, and Love', in Perspectives on Political Science 41(1): 11-18

Aquinas, Thomas 1265-1274/1912, Summa Theologica (London: Burns Oates \& Washbourne)

Audi, Robert 1991, 'Faith, Belief, and Rationality', in Philosophical Perspectives 5: 213-239

_ 2008, 'Belief, Faith, and Acceptance', in The International Journal for Philosophy of Religion 63 (1-3): 87-102

Augustine of Hippo c. 420/1955, Enchiridion on Faith, Hope and Love,

Outler A., trans. (Grand Rapids, MI: Freebooks)

Benatar, David 2006, 'What's God Got to Do With It? Atheism and Religious Practice', in Ratio 19(4): 383-400

Benton, Matthew 2017, 'Epistemology Personalized', in The Philosophical Quarterly 67(269): 813-834

- 2018, 'God and Interpersonal Knowledge', Res Philosophica 95(3): 421-447

2019, 'Epistemological Aspects of Hope', in C. Blöser and T. Stahl (eds), The Moral Psychology of Hope (Lanham, MD: Rowman and Littlefield): 135-151

— Forthcoming, 'Knowledge, Hope, and Fallibilism', in Synthese $<$ https: //doi.org/10.1007/s11229-018-1794-8>

Bishop, John 2016, 'Faith', in E. N. Zalta (ed.), The Stanford Encyclopedia of Philosophy <https://plato.stanford.edu/entries/ faith/>

${ }^{22}$ Thanks to Robert Audi, Justin D'Ambrosio, Alan Hájek, anonymous referees and editors at this journal, and to audiences at the 2017 Providence Evangelical Philosophy Society, 2018 Boston College Graduate Conference on Faith, and 2018 Beijing World Congress of Philosophy for helpful questions and comments. 
Blöser, Claudia and Titus Stahl 2017, 'Fundamental Hope and Practical Identity', in Philosophical Papers 46(3): 345-371

Born, Einar Duenger 2018, 'The Logic of Hope: A Defense of the Hopeful', in Religious Studies 54: 107-116

Bovens, Luc 1999, 'The Value of Hope', in Philosophy and Phenomenological Research 59(3): 667-681

Bratman, Michael 1987, Intentions, Plans, and Practical Reason (Cambridge: Harvard University Press)

Briggs, Rachel 2014, 'Normative Theories of Rational Choice: Expected Utility', in E. N. Zalta (ed.), The Stanford Encyclopedia of Philosophy <https://plato.stanford.edu/entries/ra tionality-normative-utility/ $>$

Buchak, Lara 2013, Risk and Rationality (Oxford: OUP)

- 2017a, 'Precis of Risk and Rationality', in Philosophical Studies 174: $2363-2368$

- 2017b, 'Faith and Steadfastness in the Face of Counter-evidence', in The International Journal for Philosophy of Religion 81(1): 113-133

Calhoun, Cheshire 2018, 'Motivating Hope', in C. Calhoun (ed.), Doing Valuable Time: The Present, the Future, and Meaningful Living (Oxford: OUP): 68-90

Chae, Lee-Ann Forthcoming, 'Hoping for Peace', in Australasian Journal of Philosophy <https://doi.org/10.1080/o0048402.2019. $1611893>$

Chignell, Andrew 2021, 'The Focus Theory of Hope', in N. Snow (ed.), Hope (Oxford: OUP)

Cohen, Jonathan 1989, 'Belief and Acceptance', in Mind 391(98): 367-389

1992, An Essay on Belief and Acceptance (New York: Clarendon Press)

Davidson, Donald 1963, 'Actions, Reasons, and Causes', in The Journal of Philosophy 60(23): 685-700

Day, J.P. 1969, 'Hope', in American Philosophical Quarterly 6(2): 89-102

Downie, R.S. 1963, 'Hope', in Philosophy and Phenomenological Research 24(2): 248-51

Duckworth, Angela 2016, Grit: The Power of Passion and Perseverance (New York: Scribner)

Godfrey, Joseph J 1987, A Philosophy of Human Hope (Dordrecht: Martinus Nijhoff Publishers) 
Howard-Snyder, Daniel 2013, 'Propositional Faith: What It Is and What It Is Not', in American Philosophical Quarterly 50(4): 357-372

Jackson, Elizabeth 2019, 'How Belief-Credence Dualism Explains Away Pragmatic Encroachment', in The Philosophical Quarterly 69(276): $511-533$

- 2020, 'The Nature and Rationality of Faith', in J. Rasmussen and K. Vallier (eds.), The New Theist Response to the New Atheists (New York: Routledge): 77-92

James, William 1897, The Will to Believe (London: Longmans, Green $\& \mathrm{Co})$

Jeffrey, Anne 2017, 'Does Hope Morally Vindicate Faith?' in The International Journal for the Philosophy of Religion 81: 193-211

Kleinschmidt, Shieva 2017, 'Atheistic Prayer', in Faith and Philosophy 34(2): 152-175

Kvanvig, Jonathan 2016, 'The Idea of Faith as Trust: Lessons in NonCognitivist Approaches to Faith', in M. Bergmann and J. Brower (eds.), Reason and Faith: Themes from Richard Swinburne (Oxford: OUP): 4-26

- 2013, 'Affective Theism and People of Faith', in Midwest Studies in Philosophy 37(1): 109-128

Locke, Dustin 2015, 'Practical Certainty', in Philosophy and Phenomenological Research 90(1): 72-95

Malcolm, Finlay and Michael Scott 2016, 'Faith, Belief, and Fictionalism', in Pacific Philosophical Quarterly 98: 257-274

Marcel, Gabriel 1951/2010, Homo Viator: An Introduction to a Metaphysic of Hope, trans. E. Craufurd and P. Seaton (South Bend: St. Augustine's Press)

Martin, Adrienne M 2013, How We Hope: A Moral Psychology (Princeton: Princeton University Press)

McGeer, Victoria 2004, 'The Art of Good Hope', in The Annals of the American Academy of Political and Social Sciences 592: 100-127

McKaughan, Daniel 2013, 'Authentic Faith and Acknowledged Risk: Dissolving the Problem of Faith and Reason', in Religious Studies 49: 101-124

Meirav, Ariel 2009, 'The Nature of Hope', in Ratio 22(2): 216-33

Milona, Michael 2019, 'Finding Hope', in The Canadian Journal of Philosophy 49(5): 710-729

- Forthcoming, 'Discovering the Virtue of Hope', in The European Journal of Philosophy

Mittleman, Alan 2009, Hope in a Democratic Age (Oxford: OUP) 
Morton, Jennifer M. and Sarah K. Paul 2019, 'Grit', Ethics 129: 175-203

Mugg, Joshua 2016, 'In Defence of the Belief-Plus Model of Faith', in The European Journal for Philosophy of Religion 8(2): 201-219

Palmqvist, Carl-Johan 2019, 'Faith and Hope in Situations of Epistemic Uncertainty', in Religious Studies 55(3): 319-335

Pettit, Philip 2004, 'Hope and Its Place in Mind', in The Annals of the American Academy of Political and Social Science 592(1): 152-165

Pojman, Lewis 1986, 'Faith without Belief', in Faith and Philosophy 3(2): $157-176$

Rettler, Bradley 2018, 'Analysis of Faith', in Philosophy Compass 13(9): 1-10

Rioux, Catherine 2020a, 'Hope as the Attitude of Gritty Agents', unpublished manuscript

— 2020b, 'A Higher-Order Approach to Diachronic Continence', unpublished manuscript

Ross, Jacob, and Mark Schroeder 2014, 'Belief, Credence, and Pragmatic Encroachment', in Philosophy and Phenomenological Research 88(2): 259-288

Schwitzgebel, Eric 2019, 'Belief', in E. N. Zalta, (ed.), The Stanford Encyclopedia of Philosophy <https://plato.stanford.edu/entries/be lief/>

Stockdale, Katie 2019, 'Social and Political Dimensions of Hope', in The Journal of Social Philosophy 50: 28-44

Vahid, Hamid 2009, 'Alston on Belief and Acceptance in Religious Faith', in The Heythrop Journal 50(1): 23-30

Walker, Margaret Urban 2006, Moral Repair: Reconstructing Moral Relations after Wrongdoing (Cambridge: CUP)

Wedgwood, Ralph 2012 'Outright belief', in Dialectica 66(3): 309-329

Weirich, Paul 2004, 'Belief and Acceptance', in I. Niiniluoto, M.

Sintonen and J. Wolenski, (eds.), The Handbook of Epistemology (Dordrecht: Kluwer Academic): 499-520 